\title{
Effective Therapeutic Feeding with Chickpea Sesame Based Ready-to-Use Therapeutic Food (CS-RUTF) in Wasted Adults with Confirmed or Suspected AIDS
}

\author{
Paluku Bahwere ${ }^{1,2}$, Hedwig Deconinck ${ }^{3}$, Theresa Banda ${ }^{1}$, Steve Collins ${ }^{1}$ \\ ${ }^{1}$ Valid International, Oxford, UK; ${ }^{2}$ School of Public Health, Free University of Brussels, Brussels, Belgium; ${ }^{3}$ Save the Children, \\ Westport, USA. \\ E-mail: \{paluku, theresa, steve\}@validinternational.org, hdeconinck@gmail.com
}

Received September $1^{\text {st }}, 2011$; revised October $7^{\text {th }}, 2011$; accepted October $23^{\text {rd }}, 2011$.

\begin{abstract}
Wasting has been observed as a common feature of the human immunodeficiency virus (HIV) disease since the first reports and its presence increases the risk of death. There is no consensus on how to manage wasting associated with $H I V$. The goal of this study was to assess the effectiveness of a locally made Chickpea Sesame Based RUTF (CS-RUTF) in treating wasting associated with HIV in developing countries. Chronically sick adults from Mangochi Health District (Malawi) with wasting and confirmed or presumptive clinical diagnosis of HIV were recruited for the study. Subjects received a daily ration of 500 grams of CS-RUTF for 3 to 5 months. Nutrition status changes and mortality were used to assess the effectiveness of the intervention. There were 3 patterns of anthropometric responses continuous weight gain $(W G)$, static weight (SW) and continuation weight loss $(W L)$. The distribution of the 3 patterns is $53.9 \%(82 / 154)$ for the WG pattern, 9.1\% (14/154) for the SW pattern and 37.0\% (57/154) for the WL pattern. For the WG pattern, the overall median weight gain was 4.6 (2.4 to 7.1) $\mathrm{kg}$. It was 5.7 (3.5 to 7.8) $\mathrm{kg}$ for those who completed 3 months of supplementation. MUAC and BMI changes followed similar pattern than weight change. Not being on HAART, acute diarrhoea during follow up, episode of reduced appetite during follow up, missing at least one visit were identified as risk factors for intervention failure. Overall, 38.5\% (72/187) of study participants died during the intervention. In conclusion, despite that the study confirms the limited impact of food based interventions on mortality among wasted HIV positive individuals, it also suggests that supplementation with CS-RUTF may be an effective intervention for reversing wasting associated with HIV if combined with HAART and specific treatment of severe opportunistic infection causing diarrhoea and reducing appetite.
\end{abstract}

Keywords: AIDS, Wasting, Nutrition Therapy, Ready-to-Use Therapeutic Food

\section{Introduction}

HIV/AIDS is not just a public health problem but it is a major developmental concern of the century [1-5]. The pandemic has reduced the size and productivity of the workforce as a result of excess mortality, prolonged illness that causes frequent absenteeism and a reduced working capacity $[4,6-8]$. Wasting, defined conventionally as the involuntary loss of $10 \%$ or more of one's premorbid weight, contributes to this situation through an association with fatigue and an increased risk of death [9-12].

Wasting has been observed as a feature of HIV disease since the first reports of the condition [13,14]. In industrialized countries, the prevalence of wasting in People Living with HIV (PLHIV) varies between 17 percent and $50 \%$ [15-18]. In developing countries, this prevalence is difficult to determine as premorbid weight is rarely known, however, studies using the criteria Body Mass Index $(\mathrm{BMI})<18.5 \mathrm{~kg} / \mathrm{m}^{2}$ or MUAC $<22.0 \mathrm{~cm}$ for women and $<23.0 \mathrm{~cm}$ for men, have demonstrated a prevalence at the time of commencing HAART of up to $25 \%[12,19-22]$. This is almost certainly an underestimation of the true prevalence of wasting as many more PLHIV loose more than $10 \%$ of their premorbid weight 
without meeting the BMI or MUAC criteria mentioned above.

There is now good evidence to confirm that the presence of wasting is associated with increasing risk of mortality in PLHIV [11,12,16,19,23-25]. In the preHAART era, studies conducted in high-income countries showed that wasting was associated to up to $13.7 \%$ of death with individuals with moderate to severe wasting having 1.9 and 6.7 more risk of dying within the year, respectively $[25,26]$. Similar results have been reported in West Africa where Van der Sande et al. noted that the baseline BMI recorded within three months of the diagnosis of HIV infection is a strong and independent predictor of mortality and the predictive power was as good as that of CD4 cell count [19]. In their study, patients with a BMI below 16 were 6.4 times more likely to die than individuals with a BMI above $22 \mathrm{~kg} / \mathrm{m}^{2}$ and those with BMI below $18 \mathrm{~kg} / \mathrm{m}^{2}$ were 3.4 times more likely to die than those with a BMI above $18 \mathrm{~kg} / \mathrm{m}^{2}$ [19]. Studies have shown that even after the advent of Highly Active AntiRetroviral Therapy (HAART), the mortality among PLHIV with wasting at the time of commencing HAART remain high $[11,12,21]$. In a retrospective study evaluating the outcomes of patients on HAART in Singapore, Paton et al found that BMI $<17$ was a strong independent predictor of death with an adjusted hazard ratio of 2.2 [11]. A study in Malawi also found that patients with $\mathrm{BMI}<16,16$ to 16.9 and 17 to 18.4 had, after adjustment for confounding, a 6.0, 2.4 and 2.1 fold higher risk of dying respectively within the first 3 months of HAART treatment than those who had a BMI $\geq 18.5$ $\mathrm{kg} / \mathrm{m}^{2}$ at HAART commencement [12]. Similar results have been reported for many other developing countries including Burkina Faso, Tanzania and Zambia [21, 27-31].

At present there is no consensus on how to manage PLHIV with wasting or other forms of malnutrition [32]. Various studies have examined nutritional interventions in the form of oral supplementation or total parenteral nutrition and many of these studies have reported persistence of high mortality in wasted adults receiving nutrition supplementation in combination or not with HAART [23,32-34]. The most popular nutrition supplement used in resource-poor countries to combat wasting in PLHIV is corn soya blend mixed with vegetable oil. The first scientific evaluation on the impact of this intervention was conducted in Malawi within the Bangwe home based care programme, indicated that it had a limited impact on the nutritional status and the survival of PLHIV admitted in the programme with advanced HIV [23]. In contrast to the Bangwe findings, anecdotal results obtained with the Ready to Use Therapeutic Food (RUTF) in Malawi in children as well as in adults were encouraging [35-37]. Up to $59 \%$ of HIV positive malnourished children treated in Dowa community-based Therapeutic Care (CTC) programme, recovered with RUTF alone in absence of HAART. The majority of those who recovered retained a good nutritional status after an average 15.5 months after discharge from the programme [35]. A pilot programme conducted by Valid International has also shown that RUTF can be used to treat malnutrition in chronically sick adults at home through home based care programme structures [36]. In this programme, $54 \%$ of bedridden adults improved their physical activity by at least one grade in the Karnofsky score within the first 2 weeks of the treatment; this was accompanied with improvements in nutritional status [36]. The goal of the study was to confirm the findings of the pilot study and identify factors affecting the effectiveness of therapeutic feeding with RUTF and describe its benefits on a larger study group. This paper reports on the impact of the therapeutic feeding intervention on nutrition parameters, including anthropometric parameters, haemoglobin, physical activity performance measured by the Karnofsky score and the handgrip, and body composition.

\section{Methods}

\subsection{Setting}

The study was implemented in the Mangochi Health District, Malawi, between October 2006 and May 2007. Mangochi lies at the southern tip of Lake Malawi. The district had a population of around 778,338 in 2007. Although fishing is the main income generating activity of the district, subsistence farming employs $90 \%$ of the population. The estimated prevalence of HIV in the district was $21 \%$ in 2007 . In the district, stigmatization is a major barrier to access health care. As a consequence both HIV testing and enrolment HAART programme are often delayed and the compliance poor. Reasons cited for this include fear of stigmatization, cost of transport and food insecurity. Save the Children and ten Community Based Organisations (CBOs) work to support PLHIV and all the participants were recruited within their catchment's areas. Free HAART was available in the area from government or mission hospital and one of the 10 CBOs offered transportation to their clients from the $\mathrm{CBO}$ office to the HAART clinic.

\subsection{Study Design and Procedures}

Chronically sick adults were eligible for enrolment in the study if they met one of the following criteria: 1) living in the catchment area of a participating CBO; 2) confirmed or presumptive clinical diagnosis of HIV and 3) 
MUAC $<22.0 \mathrm{~cm}$ or BMI $<17 \mathrm{~kg} / \mathrm{m}^{2}$ or confirmed weight loss $>10 \%$ or bilateral pitting oedema of the feet or legs. Exclusion criteria included diabetes, hypertension, known renal insufficiency, long term physical disability or inability to eat.

The key interventions included 1) nutrition education and counselling to participants and their caregivers and 2) Nutrition Support with Chickpea Sesame Based RUTF (CS-RUTF) and 3) Medical support: including Cotrimoxazole prophylaxis and treatment for minor diseases, referral and linkage with nearest health facility for management of severe medical conditions and the nearest HAART clinic for treatment.

At admission, MUAC, weight, height, sitting height and presence of bilateral oedema were checked to confirm nutrition status. Participants were classified as wasted if they had a MUAC $<22.0 \mathrm{~cm}$ for women and $<23.0 \mathrm{~cm}$ for men or BMI $<18.5 \mathrm{~kg} / \mathrm{m}^{2}$. They were classified as severely wasted when BMI was $<16 \mathrm{~kg} / \mathrm{m}^{2}$ or MUAC $<18.5 \mathrm{~kg} / \mathrm{m}^{2}$.

The physical activity performance was measured using the Karnofsky scores and Eastern Cooperative Oncology Group (ECOG) score and handgrip. A brief medical history and physical examination was conducted to determine the clinical WHO HIV stage and identify existing morbidity. Blood was taken, to measure haemoglobin and CD4 count. The haemoglobin level was determined using a Hemacue haemoglobinometer (HeamaCue AB, Angelholm,Sweden) and participants with haemoglobin below $8 \mathrm{~g} / \mathrm{dl}$ were classified as severely anaemic. Analyses for estimation of CD4 count were done using Fluorescence Activated Cell Sorter (FACS) count flow cytometer (Becton Dickinson, Singapore) at the University of North Carolina Project Laboratory in Lilongwe.

Study participants were followed up at week 2, month1 and then monthly during the therapeutic feeding phase. After discharge from the therapeutic feeding phase, study participants were followed up quarterly during 12 months. Clinical and nutrition data were collected at each follow up. Additionally, information on CS-RUTF intake was collected during the therapeutic feeding phase. Calculation of CS-RUTF intake was based on self-reporting (total number of pots eaten and daily intake during the period under review). This information was completed by the counting of terminated empty pots. Household food security conditions and the intake of additional foods were assessed at admission and during follow up. The intake of additional foods was assessed on a 24-hour and a 7-day food intake recall approach.

Study participants were discharged from the therapeu- tic feeding phase if they reached the discharge criteria of MUAC $>23.0 \mathrm{~cm}$ (minimum and maximum stay in the programme of 12 and 20 weeks) or if they decided to abandon the study or if they moved out from the study catchment area of the study or if they died. For the follow up after therapeutic feeding phase, participants were censored if they completed the 12 months or if they moved out of the study area or if they died.

For this study, the weight loss prior to admission was estimated using the mean weight of rural adults Malawian published by Zverev and Chisi. Nutrition status improvement was assed using both physical activity performance criteria and anthropometric criteria. The physical activity performance criteria included improvement in Karnofsky score and increase in handgrip while the anthropometric criteria include weight, MUAC and BMI gains and achievement of the MUAC discharge criteria. We arbitrary defined static weight as a weight change $\leq$ $500 \mathrm{~g}$.

\subsection{Study Food}

The composition of the CS-RUTF has been previously published [36]. Subjects were recommended to consume two pots $(500 \mathrm{~g})$ providing 2600 kilocalories, $61.5 \mathrm{~g}$ of proteins and $>1$ RDI for all the vitamins and minerals per day. The aim was to provide the daily requirements but participants were allowed to eat other family food because it was not suitable and impossible to impose a monotonic diet for 3 to 5 months

\subsection{Data Analyses and Statistics}

Data analyses were performed using SPSS 10.0 for Windows (SPSS Inc., Chicago, IL, USA). Quantitative data for normally distributed variables were described using means and standard deviation (SD) and compared using Student's t-test for 2 group comparisons and ANOVA test for multiple group comparisons; non-normally distributed variables were described using median and inter-quartile range (IQR) and compared using the Kruskall Wallis test. Dichotomous variables were compared using the Pearson or the McNemar $\chi^{2}$ test as appropriate. The associations between change in nutrition status and variables upon admission and follow up were explored using the bivariate analysis followed by a stepwise logistic regression. For the logistic regression analysis, all the methods (enter, forward and backward) were used to identify the potential independent predictors. The enter method was used for the final models that included all variables selected by each of the methods. Wald statistics were used to test the statistical significance of the variables retained in the final model. 


\subsection{Ethical Considerations}

The research protocol was submitted to the National Health Sciences Research Committee (NHSRC) and the NHSRC provided ethical approval under the number 407. Participation was voluntary. Before inclusion participants signed a consent form after receiving complete information on study objectives and procedures. The consent form that was in englesh and local language included the authorisation to participate into the study and of the publication of findings. The participant had the right to withdraw from the study at any time, during the study period.

\section{Results}

\section{Characteristics of Participants and Their}

\section{Households}

Overall, 194 individuals were enrolled into the study. Among them, 59.8\% (116/194) had an HIV confirmed diagnosis. From the remaining, 7 later tested HIV nega- tive (Negative Eliza test and CD4 count between 645 and 1464 cells $/ \mu 1$.) and the others were later confirmed HIV-infected. Based on the WHO clinical staging for HIV, almost all participants had clinical advanced AIDS. While $25.7 \%$ (48/187) had started HAART before enrolment, $5.9 \%(11 / 187)$ started HAART during the therapeutic feeding phase. Table 1 shows that the majority of participants enrolled were female and young. More than a third had never attended school. $79.4 \%$ of the study participants had stopped working because of illness and more than $60 \%$ were bedridden (Karnofsky score < $50 \%$ ) and required considerable support in daily living activities. Almost one third of them described their own health condition as poor, very poor or terrible. Coping strategies for household food insecurity were common among participants: $93.0 \%$ (180/194) used certain coping strategies before enrolment. Only $2.6 \%$ of participants had eaten food from the 6 different food group the day

Table 1. Socio-demographic profile and health condition of the participants at admission.

\begin{tabular}{|c|c|c|}
\hline & $\mathrm{n}$ & $\%$ \\
\hline \multicolumn{3}{|l|}{ Sex } \\
\hline Male & 58 & 31.0 \\
\hline Female & 129 & 69.0 \\
\hline Total & 187 & 100.0 \\
\hline \multicolumn{3}{|l|}{ Age } \\
\hline Mean (SD) & \multicolumn{2}{|c|}{34.1 (SD 9.2) } \\
\hline$<18$ year & 3 & 16 \\
\hline $18-49$ years & 164 & 88.2 \\
\hline$>49$ years & 19 & 10.2 \\
\hline Total & 186 & 100.0 \\
\hline \multicolumn{3}{|l|}{ Schooling level } \\
\hline Never attend school & 65 & 34.8 \\
\hline Complete or incomplete primary school & 105 & 56.1 \\
\hline Secondary school & 12 & 6.4 \\
\hline Missing data & 5 & 2.7 \\
\hline Total & 187 & 100.0 \\
\hline \multicolumn{3}{|l|}{ Working status } \\
\hline Working & 25 & 13.4 \\
\hline Not working & 155 & 82.9 \\
\hline Missing data & 7 & 3.7 \\
\hline Total & 187 & 100.0 \\
\hline
\end{tabular}




\section{Karnofsky score}

90: Able to perform normal activity; minor signs and symptoms of disease

80: Able to perform normal activity with effort;some signs/symptoms of disease

70: Cares for self, unable to perform normal activity or to do active work

60: Requires occasional assistance but is able to care for most of own needs

30: Hospitalisation indicated although death not imminent; severely disabled

Total

Self rating of health condition

Good or Excellent

Fair

Poor

Very poor or terrible

Data missing

HIV WHO clinical stage

Stage 4

CD4 count (Cells/microliter)

Median (IQR)

165 (IQR 85.5 - 348.0)

$<50$

$50-<100$

$100-<200$

$200-<350$

Handgrip (kg) 
before admission into the study.

The nutrition status at admission is described in Table 2. Of note, two third of the participants had an estimated weight loss greater than $10 \%$ and more than one third of participants were found to be severely wasted with some having also bilateral pitting oedema. The average haemoglobin was very low and severe anaemia was observed in more than a third of the participants. At the time of enrolment, women had likely loss more weight than men [mean \% (SD) weight loss $18.1(10.8) \%$ for women and $7.8(13.4) \%$ for men; $p<0.001]$. Similarly, the estimated reduction in MUAC was more important in women [mean (SD) $2.6(0.7) \mathrm{cm}$ for women and $1.6(0.6)$ $\mathrm{cm}$ for men; $\mathrm{p}<0.001$ ]

At admission, all the 187 participants accepted to eat RUTF after tasting it but 9 later stopped taking CSRUTF giving an overall dropout rate of 4.8\% (9/187). Self reported intake average (SD) was 255.3 (139.0) $\mathrm{g} /$ day corresponding to $32.1(19.2) \mathrm{kcal} / \mathrm{kg} /$ day.

Anthropometric response to the therapeutic feeding could be calculated for 154 out of 187 participants who had at least one follow up visit. The overall median (IQR) of weight gain at discharge was $0.9(-1.9-5.1) \mathrm{kg}$. It was $2.8(-1.7-6.6) \mathrm{kg}$ for those who received the supplement for a minimum of 3 months. There were 3 patterns of anthropometric responses based on weight change namely continuous weight gain (WG), static weight (SW) and continuation of weight loss (WL). The distribution of the 3 patterns is $53.9 \%(82 / 154)$ for the WG pattern, $9.1 \%$ $(14 / 154)$ for the SW pattern and $37.0 \%(57 / 154)$ for the WL pattern. The mean (SD) of reported daily CS-RUTF intake per body weight was $36.2(20.0) \mathrm{Kcal} / \mathrm{kg} /$ day for the WG pattern, $30.2(18.7) \mathrm{Kcal} / \mathrm{kg} /$ day for the SW pattern and $29.6(15.1) \mathrm{Kcal} / \mathrm{kg} /$ day for the WL pattern $(\mathrm{p}=$ $0.104)$. The duration into the therapeutic phase was also not significantly different and was 99.4 (24.9) days fro the WG pattern, 108 (32.6) days for the SW pattern and 91.9 (35.5) days for the WL pattern, respectively $(\mathrm{p}=$ 0.135 ). The median (IQR) weight gain according to the anthropometric pattern response were $4.6(2.4$ to 7.1$) \mathrm{kg}$ for the WG pattern, -0.1 ( -0.4 to 0.2$) \mathrm{kg}$ for SW pattern and $-2.8(-3.9$ to -1.7$) \mathrm{kg}$, for the WL pattern. Among those who remained in the programme for a minimum of 3 months, the median (IQR) weight gain were 5.7 (3.5 to $7.8) \mathrm{kg}$ for WG pattern ( $\mathrm{n}=58),-0.4(-0.5$ to 0.0$) \mathrm{kg}$ for the SW pattern $(\mathrm{n}=6)$ and $-2.5(-4.5$ to -1.8$) \mathrm{kg}$ for WL pattern $(\mathrm{n}=28)$. The changes in MUAC, BMI, and handgrip for the different patterns are presented in Table 3. The differences in changes of MUAC, BMI and handgrip from admission to discharge were statistically significant. The difference was more important when only those who received the therapeutic food for at least 3 months were
Table 2. Nutrition status at admission.

\begin{tabular}{|c|c|c|}
\hline Variable & $\mathbf{n}$ & $\%$ \\
\hline \multicolumn{3}{|c|}{ Estimated percentage weight loss } \\
\hline Mean (SD) & \multicolumn{2}{|c|}{$15.9(\mathrm{SD} 12.8)$} \\
\hline$\geq 10 \%$ & 122 & 65.2 \\
\hline $5 \%-<10 \%$ & 27 & 14.4 \\
\hline$<5 \%$ & 33 & 17.6 \\
\hline Missing & 5 & 2,7 \\
\hline Total & 187 & 100.0 \\
\hline \multicolumn{3}{|l|}{ MUAC } \\
\hline Mean (SD) & \multicolumn{2}{|c|}{$19.6(\mathrm{SD} 1.9)$} \\
\hline$<16.0$ & 7 & 3.7 \\
\hline $16.0<18.5$ & 38 & 20.3 \\
\hline $18.5<22.0$ & 127 & 67.9 \\
\hline$\geq 22.0$ & 12 & 6.4 \\
\hline Data missing & 3 & 1.6 \\
\hline Total & 187 & 100.0 \\
\hline \multicolumn{3}{|l|}{ BMI } \\
\hline Mean (SD) & \multicolumn{2}{|c|}{$16.3(\mathrm{SD} 1.9)$} \\
\hline$<16.0$ & 68 & 36.4 \\
\hline $16.0<17.0$ & 37 & 19.8 \\
\hline $17.0<18.5$ & 51 & 27.3 \\
\hline$\geq 18.5$ & 20 & 10.7 \\
\hline Data missing & 11 & 5.9 \\
\hline Total & 187 & 100.0 \\
\hline \multicolumn{3}{|l|}{ Oedema } \\
\hline Present & 25 & 13.4 \\
\hline Absent & 162 & 86.6 \\
\hline Total & 187 & 100.0 \\
\hline \multicolumn{3}{|l|}{ Hemoglobin (g/l) } \\
\hline Mean (SD) & \multicolumn{2}{|c|}{8.8 (SD 1.2) } \\
\hline$<8.0$ & 61 & 32.6 \\
\hline$\geq 8.0$ & 103 & 55.1 \\
\hline Data missing & 23 & 12.3 \\
\hline Total & 187 & 100.0 \\
\hline
\end{tabular}


Table 3. Changes in anthropometric parameters and handgrip according to the response pattern.

\begin{tabular}{|c|c|c|c|}
\hline Variables & $\mathbf{n}$ & Median (IQR) & $\mathbf{p}$ \\
\hline \multicolumn{4}{|l|}{ ALL participants } \\
\hline \multicolumn{4}{|l|}{ MUAC (cm) } \\
\hline Continous weight gain & 83 & $2.4(1.2$ to 3.8$)$ & \\
\hline Static weight & 14 & $-0.2(-0.7$ to 0.8$)$ & $\mathrm{p}<0.001$ \\
\hline Continous weight loss & 57 & $-0.8(-1.5$ to 0.1$)$ & \\
\hline \multicolumn{4}{|l|}{ BMI $\left(\mathrm{kg} / \mathrm{m}^{2}\right)$} \\
\hline Continous weight gain & 83 & $1.7(0.8$ to 2.7$)$ & \\
\hline Static weight & 14 & $0.0(-0.2$ to 0.0$)$ & $\mathrm{p}<0.001$ \\
\hline Continous weight loss & 57 & $-1.1(-1.6$ to -0.7$)$ & \\
\hline \multicolumn{4}{|l|}{ Handgrip (kg) } \\
\hline Continous weight gain & 82 & $2.6(-0.3$ to 6.5$)$ & \\
\hline Static weight & 13 & $-0.2(-4.0$ to 1.5$)$ & $\mathrm{p}<0.001$ \\
\hline Continous weight loss & 54 & $-2.4(-4.5$ to 0.4$)$ & \\
\hline \multicolumn{4}{|c|}{$\begin{array}{l}\text { Supplemented for at least } \\
3 \text { months }\end{array}$} \\
\hline \multicolumn{4}{|l|}{ MUAC (cm) } \\
\hline Continous weight gain & 59 & $3.2(2.2$ to 4.2$)$ & \\
\hline Static weight & 6 & $0.5(-1.2$ to 1.7$)$ & $\mathrm{p}<0.001$ \\
\hline Continous weight loss & 29 & $-0.6(-1.8$ to 0.7$)$ & \\
\hline \multicolumn{4}{|l|}{ BMI (kg/m²) } \\
\hline Continous weight gain & 59 & $2.3(1.1$ to 3.0$)$ & \\
\hline Static weight & 6 & $-0.1(-0.2$ to 0.0$)$ & $\mathrm{p}<0.001$ \\
\hline Continous weight loss & 29 & $-1.2(-1.7$ to -0.7$)$ & \\
\hline \multicolumn{4}{|l|}{ Handgrip (kg) } \\
\hline Continous weight gain & 59 & $5.1(1.7$ to 8.7$)$ & \\
\hline Static weight & 6 & $-1.6(-5.9$ to 0.1$)$ & $\mathrm{p}<0.001$ \\
\hline Continous weight loss & 29 & $-2.2(-5.0$ to 0.4$)$ & \\
\hline
\end{tabular}

compared (Table 3).

The increase in proportion of participants able to perform all the activity of daily living increased from $18.3 \%$ $(15 / 82)$ to $69.5 \%(57 / 82)$ for the WG group (MacNemar test $\mathrm{p}<0.001)$ and from $13.9 \%(13 / 72)$ to $33.3 \%(24 / 72)$ for the combined SW and WL group (MacNemar test $\mathrm{p}=$ 0.030 ). For self perception of health condition, the proportion of those judging their health condition to be fair to excellent increased significantly from $42.7 \%(35 / 82)$ to $89.0 \%(73 / 82)$ for the WG group $(\mathrm{p}<0.001)$ while the increase that was from $43.7 \%(31 / 71)$ to $62.0 \%(44 / 71)$ was not statistically significant for the combined SW and WL group $(p=0.597)$. Overall, 38.5\% $(72 / 187)$ of study participants died. The mortality was $19.3 \%$ (16/83) for the WG group, $35.7 \%(5 / 14)$ for the $\mathrm{SW}$ group and $47.4 \%(27 / 57)$ for the WL group $(\mathrm{p}=0.002)$. Out of the 33 for whom weight change profile could not be calculated, $72.7 \%$ (24/33) died. Among the WG group, 49.4\% (41/83) fulfilled the discharge criteria of MUAC $\geq 23 \mathrm{~cm}$.

Table 4 presents the parameters recorded at admission or during the supplementation phase associated with weight gain in bivariate and logistic regression analyses. Of note, being on HAART and adhering to the number of visits were significantly and independently associated with increased chances of nutritional status improvement while the occurrence of episodes of acute diarrhoea, and complaint of poor appetite during supplementation negatively affected weight change.

As shown on Figure 1, the percentage of patients belonging to the WG varied according to the number of risk factors (not yet on HAART, acute diarrhoea during follow up, episode of reduced appetite during follow up, missing at least one visit). All participants who did not have any of the risk factors gained weight while only $14.3 \%$ of those with all the risk factors were classified as belonging to WG pattern group $(\mathrm{p}<0.001)$. The mean (SD) weight gain was 6.1 (2.9) $\mathrm{kg}$ for those without any of the risk factor, $3.9(5.2) \mathrm{kg}$ in presence of 1 risk factor, $1.4(4.9) \mathrm{kg}$ in presence of 2 risk factors, $-0.8(3.5) \mathrm{kg}$ in presence of 3 risk factors and -2.1 (2.9) $\mathrm{kg}$ in presence of 4 risk factors.

\section{Discussion}

The protocol for the management of wasting in HIV individuals from household from food insecure settings is yet to be established [32,38-40]. This situation is blamed on the absence of evidence that can help developing sound guidelines $[32,41]$. The present study has contrib.uted on the development of the evidence by demonstrating that wasting in PLHIV living in a context of widespread household food insecurity can be effectively reversed with fortified energy dense food such us CSRUTF and that the effectiveness may be enhanced when the supplementation is integrated to other therapeutic intervention including HAART and appropriate treatment of underlying opportunistic infection.

Wasting remains an important comorbidity in AIDS patients in populations with as it is associated with increased mortality and its frequency remains high [11, $12,21,27,31,34]$. A recent large study that evaluated the prevalence among patient starting HAART in Lusaka found that $17 \%$ of the 40,788 registered during the study 
Table 4. Admission characteristics associated with weight gain pattern.

\begin{tabular}{|c|c|c|c|c|c|c|}
\hline \multirow{2}{*}{ Variable } & \multirow{2}{*}{$\mathbf{n}$} & \multirow{2}{*}{$\%$ gained weight } & \multicolumn{2}{|c|}{ Unadjusted OR } & \multicolumn{2}{|c|}{ Adjusted OR } \\
\hline & & & OR $(95 \% \mathrm{CI})$ & $\mathbf{p}$ & OR (95\% CI) & $\mathbf{p}$ \\
\hline \multicolumn{7}{|l|}{ Model for admission parameters } \\
\hline \multicolumn{7}{|l|}{ ART status } \\
\hline Commenced prior to enrollment & 39 & 76.9 & $4.0(1.6-10.0)$ & $<0.001$ & $2.7(1.0-7.1)$ & 0.042 \\
\hline Not commenced at enrollement & 112 & 45.5 & 1.0 & & 1.0 & \\
\hline \multicolumn{7}{|l|}{ Oral diseases } \\
\hline Present & 15 & 26.7 & $0.3(0.1-1.0)$ & 0.028 & $0.3(0.1-1.1)$ & 0.066 \\
\hline Absent & 136 & 56.6 & 1.0 & & 1.0 & \\
\hline \multicolumn{7}{|l|}{ HIV testing status } \\
\hline Tested at enrollment & 85 & 62.4 & $2.2(0.9-4.3)$ & 0.015 & $1.6(0.7-3.5)$ & 0.230 \\
\hline Not tested at enrollment & 66 & 42.4 & 1.0 & & 1.0 & \\
\hline \multicolumn{7}{|l|}{ Gender } \\
\hline Male & 46 & 65.2 & $2.0(0.9-4.3)$ & 0.059 & $0.6(0.3-1.3)$ & 0.222 \\
\hline Female & 105 & 48.6 & 1.0 & & 1.0 & \\
\hline \multicolumn{7}{|l|}{ Model for incident events } \\
\hline \multicolumn{7}{|l|}{ ART status } \\
\hline Commenced $\dagger$ & 50 & 70.0 & $2.8(1.3-6.8)$ & 0005 & $3.6(1.6-8.1)$ & 0.002 \\
\hline Not commenced & 101 & 45.5 & 1.0 & & 1.0 & \\
\hline \multicolumn{7}{|l|}{ Missed visits } \\
\hline None & 66 & 65.2 & $2.3(1.3-4.7)$ & 0.012 & $2.5(1.2-5.3)$ & 0.014 \\
\hline$>=1$ & 85 & 44.7 & 1.0 & & 1.0 & \\
\hline \multicolumn{7}{|l|}{ Complaint of reduced appetite } \\
\hline At least once during follow up & 57 & 36.8 & $0.3(0.2-0.7)$ & 0.001 & $0.4(0.2-0.9)$ & 0.024 \\
\hline No complaint & 94 & 63.2 & 1.0 & & 1.0 & \\
\hline \multicolumn{7}{|l|}{ New episode of acute diarrhea } \\
\hline At least once during follow up & 48 & 43.8 & $0.6(0.3-1.2)$ & 0.096 & $0.4(0.2-0.9)$ & 0.036 \\
\hline None & 94 & 58.3 & 1.0 & & 1.0 & \\
\hline \multicolumn{7}{|l|}{ New episode of fever } \\
\hline At least once during follow up & 57 & 36.8 & $0.4(0.2-0.9)$ & 0.017 & $0.5(0.2-1.1)$ & 0.087 \\
\hline None & 94 & 63.2 & 1.0 & & 1.0 & \\
\hline \multicolumn{7}{|l|}{ Combined model } \\
\hline \multicolumn{7}{|l|}{ ART status } \\
\hline Commenced $\dagger$ & 50 & 70.0 & $2.8(1.3-6.8)$ & 0.005 & $3.4(1.5-7.8)$ & 0.003 \\
\hline
\end{tabular}



in Wasted Adults with Confirmed or Suspected AIDS

\begin{tabular}{|c|c|c|c|c|c|c|}
\hline Not commenced & 101 & 45.5 & 1.0 & & 1.0 & \\
\hline \multicolumn{7}{|l|}{ Missed visits } \\
\hline None & 66 & 65.2 & $2.3(1.3-4.7)$ & 0.012 & $2.5(1.2-5.3)$ & 0.016 \\
\hline$>=1$ & 85 & 44.7 & 1.0 & & 1.0 & \\
\hline \multicolumn{7}{|l|}{ Complaint of reduced appetite } \\
\hline At least once during follow up & 57 & 36.8 & $0.3(0.2-0.7)$ & 0.001 & $0.4(0.2-0.9)$ & 0.028 \\
\hline No complaint & 94 & 63.2 & 1.0 & & 1.0 & \\
\hline \multicolumn{7}{|l|}{ New episode of acute diarrhea } \\
\hline At least once during follow up & 48 & 43.8 & $0.6(0.3-1.2)$ & 0.096 & $0.4(0.2-1.0)$ & 0.053 \\
\hline None & 94 & 58.3 & 1.0 & & 1.0 & \\
\hline \multicolumn{7}{|l|}{ New episode of fever } \\
\hline At least once during follow up & 57 & 36.8 & $0.4(0.2-0.9)$ & 0.017 & $0.6(0.2-1.2)$ & 0.126 \\
\hline None & 94 & 63.2 & 1.0 & & 1.0 & \\
\hline \multicolumn{7}{|l|}{ Oral disease at admission } \\
\hline Yes & 15 & 26.7 & $0.3(0.1-1.0)$ & 0.027 & $0.6(0.2-2.2)$ & 0.370 \\
\hline No & 136 & 53.6 & 1.0 & & 1.0 & \\
\hline
\end{tabular}

Not retained: peristent fever, persistent diarrhea, severe cough, hemoglobin level, CD4 count, Karnofsky score, handgrip, self perception of health condition, working status, walking status, marital status, food security condition, headache, BMI of admiss.

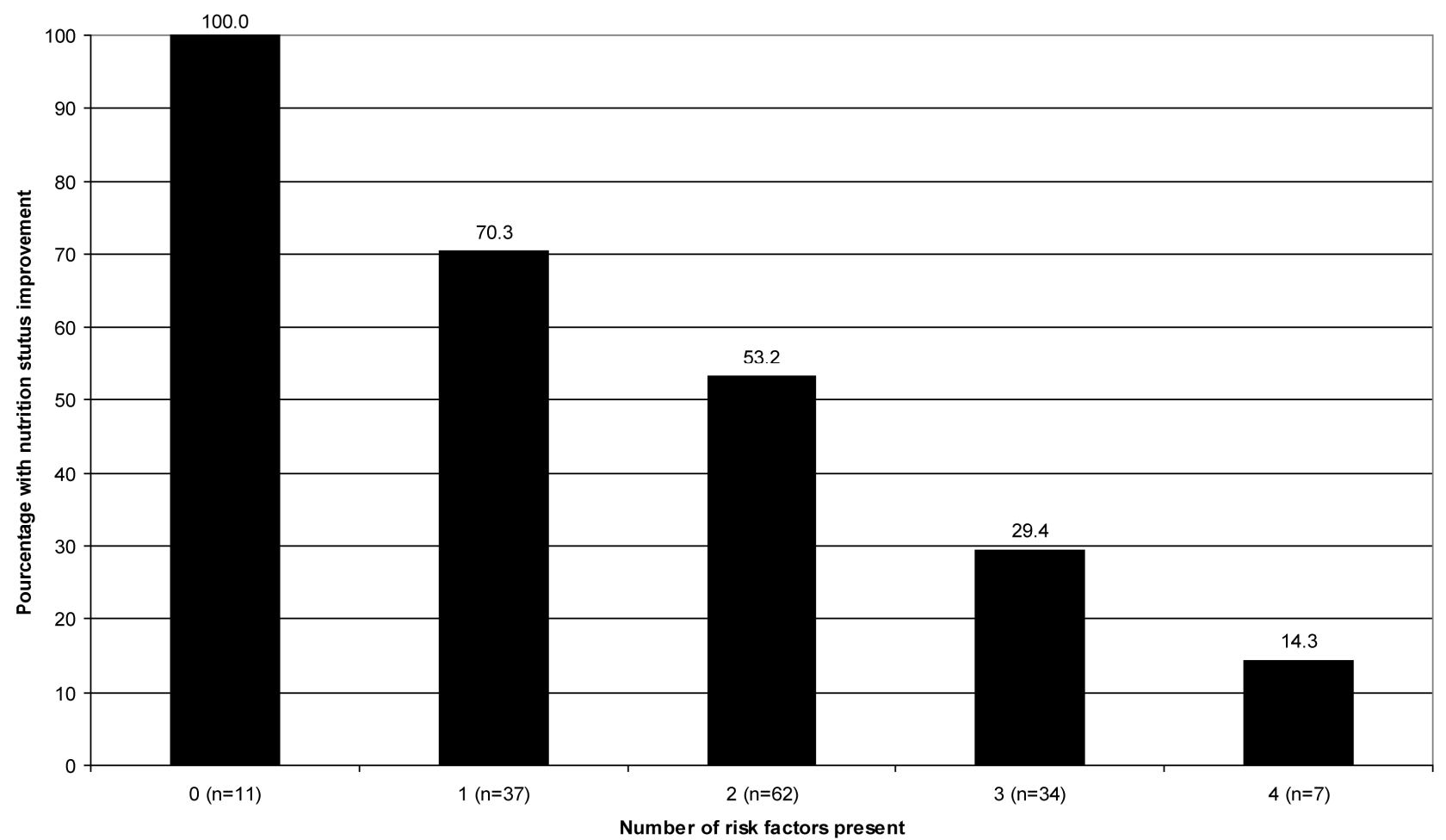

Figure 1. Percentage of participant with nutrition status improvement according to number of independent risk factors. 
period had a BMI $<17 \mathrm{~kg} / \mathrm{m}^{2}$ and the figure was $34 \%$ if the cutoff of $18.5 \mathrm{~kg} / \mathrm{m}^{2}$ was used [31]. In addition, evaluation of various HAART programmes have demonstrated that the presence of wasting at the time of commencing HAART, increases, by up to 6 times, the early (3-month) mortality $[12,21,27]$. The present study that was conducted at the start of the scale up of free HAART confirms that wasting is likely to remain common at the time of diagnosing HIV as most of the HIV infected wasted individuals enrolled into the study were not yet tested. Thus, for Malawi and most resource-poor countries wasting in PLHIV remains an important public health problem given the contribution of this pandemic to the overall mortality of young adults [42].

Given the public health importance of wasting of PLHIV, it is essential for countries affected by the HIV pandemic to identify an effective intervention that can reverse the wasting process while improving the quality of life of PLHIV. Several studies have now shown that therapeutic feeding with RUTF is a promising intervention [32,34-37]. A pilot study that included $60 \mathrm{HIV}$ wasted adults already demonstrated the acceptability and tolerance of CS-RUTF used in the present study [36]. The pilot study also demonstrated a clear link between the amount of CS-RUTF intake and weight gain [36]. In a cohort of wasted individuals staring HAART in Malawi, supplementary feeding with RUTF was associated with higher weight gain than supplementary feeding with porridge made from a corn soya fortified blended floor [34]. Several findings of the present study confirm the CSRUTF effectiveness. Despite the overall low weight gain observed in the present study and the low recovery rate, the fact that adherence to the programme doubled the chances of gaining weight, the impressive weight gain of $6 \mathrm{~kg}$ when there were no detrimental risk factor, the higher increase in proportion of those with normal physical activity performance and those rating their health condition as fair to excellent among the WG pattern group when compared to the other groups, strongly suggest that the intervention was effective.

The results of the present study showing that some of the patients had static weight or continued to loose weight despite good intake of CS-RUTF don't have to be interpreted as an indication of ineffective therapeutic feeding. The apparently poor response was rather the consequence of the chronic inflammatory process that can be controlled by the adjunction of HAART as suggested by the strong independent relationship between HAART and the response pattern. It also outlines the fact that these patients usually present other comorbidity that interfere with nutrition recovery such us diarrhoea and oral candidiasis. HIV infection and many other chronic infections contribute to the development of wasting through an inflammatory process leading to cachexia and authors have observed that a food based intervention alone cannot reverse the cachexia process [43]. Thus, the judgment on the effectiveness of a therapeutic feeding intervention in PLHIV should take into account the quality of the management of HIV itself and of the other comorbidities.

The detrimental effect on the response to therapeutic feeding interventions targeting PLHIV of factors identified in this study namely absence of HAART, diarrhoea and oral disease have been reported before [44-47]. In study carried out in the pre-HAART era, Howard et al. obtained $8 \%$ recovery rate with home parenteral nutrition after 12 months in studies conducted in north America and Europe [48]. For diarrhoea, Beaugerie et al found a direct interrelation between the clinical severity of diarrhoea and malnutrition in PLHIV, Carbonnel et al. noted that most HIV adults with weight loss of a cohort of 66 individuals had diarrhoea associated with malabsorption and Stack et al showed that weight loss in wasted HIV infected individuals with diarrhoea can occur despite a good intake of therapeutic food [44,46,49]. In regards of our findings and that of the literature cited, severe wasting should be considered as an independent criterion for initiating HAART. Interestingly, the WHO staging criteria currently include moderate involuntary weight loss $(<10 \%)$ as a stage 3 condition and severe involuntary weight loss ( $>10 \%)$ as a stage 4 condition. Unfortunately, these criteria are not practical as in many resource-poor countries premorbid weight is unknown. Consequently, the level of wasting is not always used for initiating HAART. Thus, we suggest the replacement of the weight loss criteria by criteria based on anthropometric measurement as already suggested by other authors [50,51].

The high mortality rate of $38.5 \%$ observed in the present study has to be interpreted taking into account the fact that most of people enrolled were very sick. Almost half of them rated their health condition at admission as poor or very poor, a quarter was bedridden and unable to care for self and a third of the deaths occurred among those for whom we could not calculate weight change because the death occurred within 2 weeks of admission before the second visit. Also, only $25.7 \%$ of them have started HAART at the time of admission. However, the mortality we observed is not very much higher than the 3.5 -month mortality of $27 \%$ reported by Ndekha et al. among wasted individuals treated at the teaching hospital of Malawi for whom nutritional therapy was instituted at the same time with HAART [34]. A similar high mortality of up to $88 \%$ was reported for small cohorts of AIDS patients on home parenteral nutrition in industrialized 
countries during the pre-HAART era [52-57]. This situation suggests that further reduction of the mortality of wasted PLHIV will probably depends in addition to early HAART initiation and effective therapeutic feeding, on the capacity of HAART programmes to diagnose and treat specific life threatening opportunistic infections.

\section{Conclusions}

In conclusion, despite some methodological limitations including the observational design of the study that prevent us from confidently attributing the observed effect to this intervention only, the limited number of participants that prevented some sub-analyses, the use of selfreported intake to estimate intake that may have resulted in overestimation of intake and adherence, the present study suggest that supplementation with CS-RUTF is an effective intervention for reversing wasting in PLHIV but has limited impact on mortality. Its effectiveness is likely to be improved by concomitant initiation of HAART and specific treatment of severe opportunistic infection. Thus, we recommend the use of CS-RUTF or other similar products for the management of wasting of PLHIV. In patients not yet on HAART, this intervention should not delay HAART initiation but should be used to enable and faster initiate HAART.

\section{Competing Interests}

HD had no competing interest. But all the authors work for Valid International, a company sister to Valid Nutrition a charity organization that promotes local production of Ready-To-Use Therapeutic Food. SC is also an unpaid director of Valid Nutrition. The Chickpea Sesame ReadyTo-Use Therapeutic Food used for the study was bought from Valid Nutrition in Malawi with funding from Save The Children US.

\section{Authors' Contribution}

All the authors contributed to the design, implementation, interpretation of the findings and write up.

\section{Acknowledgements}

The authors would like to acknowledge the invaluable assistance of the Save Children Malawi country office and staff and all the program participants and their families. They also acknowledge the great contribution of all Valid International Malawi staff for the success of the study. Special thanks for Laura Banks, for editing the manuscript. Funding for this work was provided by Save Children US. All the authors contributed to the design, implementation, interpretation of the findings and write up. Written consent for publication was obtained from the patients.

\section{REFERENCES}

[1] G. Anabwani and P. Navario, "Nutrition and HIV/AIDS in Sub-Saharan Africa: An Overview," Nutrition, Vol. 21, No. 1, 2005, pp. 96-99. doi:10.1016/j.nut.2004.09.013

[2] T. Atinmo and D. Oyewole, "Finding Solutions to the Nutritional Dilemmas in Africa for Child Health: HIV/ AIDS Orphans, Poverty and Hunger," Asia Pacific Journal of Clinical Nutrition, Vol. 13, 2004, p. S6.

[3] R. Danziger, "The Social Impact of HIV/AIDS in Developing Countries," Social Science \& Medicine, Vol. 39, No. 7, 1994, pp. 905-917. doi:10.1016/0277-9536(94)90203-8

[4] K. Ojo and M. Delaney, "Economic and Demographic Consequences of AIDS in Namibia: Rapid Assessment of the Costs," International Journal of Health Planning and Management, Vol. 12, No. 4, 1997, pp. 315-326. doi:10.1002/(SICI)1099-1751(199710/12)12:4<315::AID -HPM492>3.0.CO;2-A

[5] W. Hladik, J. Musinguzi, W. Kirungi, et al., "The Estimated Burden of HIV/AIDS in Uganda, 2005-2010," AIDS, Vol. 22, No. 4, 2008, pp. 503-510. doi:10.1097/QAD.0b013e3282f470be

[6] M. O. Bachmann and F. L. Booysen, "Health and Economic Impact of HIV/AIDS on South African Households: A Cohort Study," BMC Public Health, Vol. 3, No. 4, 2003, p. 14. doi:10.1186/1471-2458-3-14

[7] M. O. Bachmann and F. L. Booysen, "Relationships between HIV/AIDS, Income and Expenditure over Time in Deprived South African Households," AIDS Care, Vol. 16, No. 7, 2004, pp. 817-826. doi:10.1080/09540120412331290220

[8] M. Bakari, W. Urassa, K. Pallangyo, et al., "The Natural Course of Disease Following HIV-1 Infection in dar es Salaam, Tanzania: A Study among Hotel Workers Relating Clinical Events to CD4 T-Lymphocyte Counts," Scandinavian Journal of Infectious Diseases, Vol. 36, No. 6-7, 2004, pp. 466-473. doi:10.1080/00365540410016249

[9] D. P. Kotler, J. Wang and R. N. Pierson, "Body Composition Studies in Patients with the Acquired Immunodeficiency Syndrome," American Journal of Clinical Nutrition, Vol. 42, No. 6, 1985, pp. 1255-1265.

[10] D. P. Kotler, A. R. Tierney, J. Wang and R. N. Pierson Jr., "Magnitude of Body-Cell-Mass Depletion and the Timing of Death from Wasting in AIDS," American Journal of Clinical Nutrition, Vol. 50, No. 3, 1989, pp. 444-447.

[11] N. Paton, S. Sangeetha, A. Earnest and R. Bellamy, "The Impact of Malnutrition on Survival and the CD4 Count Response in HIV Infected Patients Starting Antiretroviral Therapy," HIV Medicine, Vol. 7, No. 5, 2006, pp. 323330. doi:10.1111/j.1468-1293.2006.00383.x

[12] R. Zachariah, M. Fitzgerald, M. Massaquoi, et al., "Risk Factors for High Early Mortality in Patients on Antiretroviral Treatment in a Rural District of Malawi," AIDS, Vol. 20, No. 18, 2006, pp. 2355-2360. doi:10.1097/QAD.0b013e32801086b0 
[13] R. D. Mugerwa, L. H. Marum and D. Serwadda, "Human Immunodeficiency Virus and AIDS in Uganda," East African Medical Journal, Vol. 73, No. 1, 1996, pp. 20-26.

[14] D. Serwadda, R. D. Mugerwa, N. K. Sewankambo, et al., "Slim Disease: A New Disease in Uganda and Its Association with HTLV-III Infection," Lancet, Vol. 326, No. 8460,1985 , pp. 849-852. doi:10.1016/S0140-6736(85)90122-9

[15] J. Ockenga, R. Grimble, C. Jonkers-Schuitema, et al., "ESPEN Guidelines on Enteral Nutrition: Wasting in HIV and Other Chronic Infectious Diseases," Clinical Nutrition, Vol. 25, No. 2, 2006, pp. 319-329. doi:10.1016/j.clnu.2006.01.016

[16] A. M. Tang, "Weight Loss, Wasting, and Survival in HIV-Positive Patients: Current Strategies," AIDS Read, Vol. 13, Suppl. 12, 2003, pp. S23-S27.

[17] G. O. Coodley, M. O. Loveless and T. M. Merrill, "The HIV Wasting Syndrome: A Review," Journal of Acquired Immune Deficiency Syndromes, Vol. 7, No. 7, 1994, pp. 681-694.

[18] U. Suttmann, J. Ockenga, O. Selberg, L. Hoogestraat, H. Deicher and M. J. Muller, "Incidence and Prognostic Value of Malnutrition and Wasting in Human Immunodeficiency Virus-Infected Outpatients," Journal of Acquired Immune Deficiency Syndromes \& Human Retrovirology, Vol. 8, No. 3, 1995, pp. 239-246. doi:10.1097/00042560-199503010-00004

[19] M. A. van der Sande, M. F. Schim van der Loeff, A. A. Aveika, et al., "Body Mass Index at Time of HIV Diagnosis: A Strong and Independent Predictor of Survival," Journal of Acquired Immune Deficiency Syndromes, Vol. 37, No. 2, 2004, pp. 1288-1294. doi:10.1097/01.qai.0000122708.59121.03

[20] S. Siziya, R. Mwendapole and A. F. Fleming, "Clinical Features of HIV Seropositive Zambian Subjects," African Journal of Medicine \& Medical Sciences, Vol. 24, 1995, pp. 173-178.

[21] J. S. Stringer, I. Zulu, J. Levy, et al., "Rapid Scale-Up of Antiretroviral Therapy at Primary Care Sites in Zambia: Feasibility and Early Outcomes," Journal of the American Medical Association, Vol. 296, No. 7, 2006, pp. 782793. doi:10.1001/jama.296.7.782

[22] A. Dannhauser, A. M. van Staden, R. E. van der, et al., "Nutritional Status of HIV-1 Seropositive Patients in the Free State Province of South Africa: Anthropometric and Dietary Profile," European Journal of Clinical Nutrition, Vol. 53, No. 3, 1999, pp. 165-173. doi:10.1038/sj.ejen.1600691

[23] C. Bowie, L. Kalilani, R. Marsh, H. Misiri and P. Cleary, "An Assessment of Food Supplementation to Chronically Sick Patients Receiving Home Based Care in Bangwe, Malawi: A Descriptive Study," Nutrition Journal, Vol. 4, 2005, p. 12. doi:10.1186/1475-2891-4-12

[24] A. M. Tang, J. Forrester, D. Spiegelman, T. A. Knox, E. Tchetgen and S. L. Gorbach, "Weight Loss and Survival in HIV-Positive Patients in the Era of Highly Active
Antiretroviral Therapy," Journal of Acquired Immune Deficiency Syndromes, Vol. 31, No. 2, 2002, pp. 230-236. doi:10.1097/00126334-200210010-00014

[25] R. Thiebaut, D. Malvy, C. Marimoutou and F. Davis, "Anthropometric Indices as Predictors of Survival in AIDS Adults. Aquitaine Cohort, France, 1985-1997," European Journal of Epidemiology, Vol. 16, No. 7, 2000, pp. 633639. doi:10.1023/A:1007696530440

[26] D. A. Wheeler, C. L. Gibert, C. A. Launer, et al., "Weight Loss as a Predictor of Survival and Disease Progression in HIV Infection. Terry Beirn Community Programs for Clinical Research on AIDS," Journal of Acquired Immune Deficiency Syndromes \& Human Retrovirology, Vol. 18, No. 1, 1998, pp. 80-85. doi:10.1097/00042560-199805010-00012

[27] A. Johannessen, E. Naman, B. J. Ngowi, et al., "Predictors of Mortality in HIV-Infected Patients Starting Antiretroviral Therapy in a Rural Hospital in Tanzania," BMC Infectious Diseases, Vol. 8, 2008, p. 52. doi:10.1186/1471-2334-8-52

[28] N. Saleri, S. Capone, V. Pietra, et al., "Outcome and Predictive Factors of Mortality in Hospitalized HIV-Patients in Burkina Faso," Infection, Vol. 37, No. 2, 2009, pp. 142-147. doi:10.1007/s15010-008-7406-7

[29] S. D. Lawn, A. D. Harries and R. Wood, "Strategies to Reduce Early Morbidity and Mortality in Adults Receiving Antiretroviral Therapy in Resource-Limited Settings," Current Opinion in HIV and AIDS, Vol. 5, 2010, pp. 18-26.

[30] J. R. Koethe and D. C. Heimburger, "Nutritional Aspects of HIV-Associated Wasting in Sub-Saharan Africa," American Journal of Clinical Nutrition, Vol. 91, No. 4, 2010, pp. 1138S-1142S. doi:10.3945/ajen.2010.28608D

[31] J. R. Koethe, A. Lukusa, M. J. Giganti, et al., "Association between Weight Gain and Clinical Outcomes among Malnourished Adults Initiating Antiretroviral Therapy in Lusaka, Zambia," Journal of Acquired Immune Deficiency Syndromes, Vol. 53, No. 4, 2010, pp. 507-513. doi:10.1097/QAI.0b013e3181b32baf

[32] J. R. Koethe, B. H. Chi, K. M. Megazzini, D. C. Heimburger and J. S. Stringer, "Macronutrient Supplementation for Malnourished HIV-Infected Adults: A Review of the Evidence in Resource-Adequate and Resource-Constrained Settings," Clinical Infectious Diseases, Vol. 49, No. 5, 2009, pp. 787-798. doi:10.1086/605285

[33] S. Mahlungulu, L. A. Grobler, M. E. Visser and J. Volmink, "Nutritional Interventions for Reducing Morbidity and Mortality in People with HIV," Cochrane Database of Systematic Reviews, Vol. 18, No. 3, 2007, CD004536.

[34] M. J. Ndekha, J. J. van Oosterhout, E. E. Zijlstra, M. Manary, H. Saloojee and M. J. Manary, "Supplementary Feeding with Either Ready-to-Use Fortified Spread or Corn-Soy Blend in Wasted Adults Starting Antiretroviral Therapy in Malawi: Randomised, Investigator Blinded, Controlled Trial," British Medical Journal, Vol. 338, 2009, b1867. 
[35] P. Bahwere, E. Piwoz, M. C. Joshua, et al., "Uptake of HIV Testing and Outcomes within a Community-Based Therapeutic Care (CTC) Programme to Treat Severe Acute Malnutrition in Malawi: A Descriptive Study," BMC Infectious Diseases, Vol. 8, 2008, p. 106. doi:10.1186/1471-2334-8-106

[36] P. Bahwere, K. Sadler and S. Collins, "Acceptability and Effectiveness of Chickpea Sesame-Based Ready-to-Use Therapeutic Food in Malnourished HIV-Positive Adults," Patient Preference and Adherence, Vol. 3, 2009, pp. 67-75.

[37] M. J. Ndekha, M. J. Manary, P. Ashorn and A. Briend, "Home-Based Therapy with Ready-to-Use Therapeutic Food Is of Benefit to Malnourished, HIV-Infected Malawian Children," Acta Paediatrica, Vol. 94, No. 2, 2005, pp. 222-225. doi:10.1111/j.1651-2227.2005.tb01895.x

[38] C. Fields-Gardner and P. Fergusson, "Nutrition Intervention in the Care of Persons with Human Immunodeficiency Virus Infection: Position of the American Dietetic Association and Dietitians of Canada," Canadian Journal of Dietetic Practice and Research, Vol. 65, No. 3, 2004, pp. 132-135. doi:10.3148/65.3.2004.132

[39] S. Grinspoon and K. Mulligan, "Weight Loss and Wasting in Patients Infected with Human Immunodeficiency Virus," Clinical Infectious Diseases, Vol. 36, Suppl. 2, 2003, pp. S69-S78. doi:10.1086/367561

[40] D. P. Kotler, "Nutritional Alterations Associated with HIV Infection," Journal of Acquired Immune Deficiency Syndromes, Vol. 25, Suppl. 1, 2000, pp. S81-S87. doi:10.1097/00042560-200010001-00013

[41] J. W. C. Hsu, P. B. Pencharz, D. C. Macallan and A. Tomkins, "Macronutrients and HIV/AIDS: A Review of Current Evidence," World Health Organization, Durban, 10-13 April 2005.

[42] H. V. Doctor and A. A. Weinreb, "Estimation of AIDS Adult Mortality by Verbal Autopsy in Rural Malawi," AIDS, Vol. 17, No. 17, 2003, pp. 2509-2513. doi:10.1097/00002030-200311210-00014

[43] L. Howard, L. Heaphey, C. R. Fleming, L. Lininger and E. Steiger, "Four Years of North American Registry Home Parenteral Nutrition Outcome Data and Their Implications for Patient Management," Journal of Parenteral and Enteral Nutrition, Vol. 15, No. 4, 1991, pp. 384-393. doi:10.1177/0148607191015004384

[44] L. Beaugerie, F. Carbonnel, F. Carrat, et al., "Factors of Weight Loss in Patients with HIV and Chronic Diarrhea," Journal of Acquired Immune Deficiency Syndromes \& Human Retrovirology, Vol. 19, No. 1, 1998, pp. 34-39. doi:10.1097/00042560-199809010-00005

[45] O. Y. Bushen, J. A. Davenport, A. B. Lima, et al., "Diarrhea and Reduced Levels of Antiretroviral Drugs: Improvement with Glutamine or Alanyl-Glutamine in a Randomized Controlled Trial in Northeast Brazil," Clinical Infectious Diseases, Vol. 38, No. 12, 2004, pp. 17641770. doi: $10.1086 / 421394$

[46] J. A. Stack, S. J. Bell, P. A. Burke and R. A. Forse, "High-Energy, High-Protein, Oral, Liquid, Nutrition Su- pplementation in Patients with HIV Infection: Effect on Weight Status in Relation to Incidence of Secondary Infection," Journal of the American Dietetic Association, Vol. 96, No. 4, 1996, pp. 337-341. doi:10.1016/S0002-8223(96)00095-8

[47] D. L. Jacobson, I. Bica, T. A. Knox, et al., "Difficulty Swallowing and Lack of Receipt of Highly Active Antiretroviral Therapy Predict Acute Weight Loss in Human Immunodeficiency Virus Disease," Clinical Infectious Diseases, Vol. 37, No. 10, 2003, pp. 1349-1356. doi: $10.1086 / 379072$

[48] L. Howard, "Home Parenteral Nutrition: Survival, Cost, and Quality of Life," Gastroenterology, Vol. 130, No. 2, 2006, pp. S52-S59. doi:10.1053/j.gastro.2005.09.065

[49] F. Carbonnel, L. Beaugerie, R. A. Abou, et al., "Macronutrient Intake and Malabsorption in HIV Infection: A Comparison with Other Malabsorptive States," Gut, Vol. 41, No. 6, 1997, pp. 805-810. doi:10.1136/gut.41.6.805

[50] P. J. Peters, I. Zulu, N. G. Kancheya, et al., "Modified Kigali Combined Staging Predicts Risk of Mortality in HIV-Infected Adults in Lusaka, Zambia," AIDS Research and Human Retroviruses, Vol. 24, No. 7, 2008, pp. 919-924. doi:10.1089/aid.2007.0297

[51] A. R. Lifson, S. Allen, W. Wolf, et al., "Classification of HIV Infection and Disease in Women from Rwanda. Evaluation of the World Health Organization HIV Staging System and Recommended Modifications," Annals of Internal Medicine, Vol. 122, 1995, pp. 262-270.

[52] H. Bakker, F. Bozzetti, M. Staun, et al., "Home Par- enteral Nutrition in Adults: A European Multicentre Survey in 1997. ESPEN-Home Artificial Nutrition Working Group," Clinical Nutrition, Vol. 18, 1999, pp. 135-140.

[53] D. M. Richards, J. J. Deeks, T. A. Sheldon and J. L. Shaffer, "Home Parenteral Nutrition: A Systematic Review," Health Technology Assessment, Vol. 1, No. 1, 1997, pp. 1-59.

[54] J. C. Melchior, C. Chastang, P. Gelas, et al., "Efficacy of 2-Month Total Parenteral Nutrition in AIDS Patients: A Controlled Randomized Prospective Trial. The French Multicenter Total Parenteral Nutrition Cooperative Group Study," AIDS, Vol. 10, No. 4, 1996, pp. 379-384. doi:10.1097/00002030-199604000-00005

[55] P. Bouletreau, M. Gerard, B. Messing, et al., "Home Parenteral Nutrition and AIDS," Clinical Nutrition, Vol. 14, Vol. 85, 1995, pp. 213-218. doi:10.1016/S0261-5614(95)80002-6

[56] P. Singer, M. M. Rothkopf, V. Kvetan, O. Kirvela, J. Gaare and J. Askanazi, "Risks and Benefits of Home Parenteral Nutrition in the Acquired Immunodeficiency Syndrome," Journal of Parenteral and Enteral Nutrition, Vol. 15, No. 1, 1991, pp. 75-79. doi: $10.1177 / 014860719101500175$

[57] B. Messing, D. Barnoud, P. Beau, et al., "A 1993-1995 Epidemiological Survey of Home Parenteral Nutrition in Approved Centers for Adults in France," Gastroenterologie Clinique et Biologique, Vol. 22, No. 4, 1998, pp. 413-418. 